\title{
Determinants of Risky Sexual Behaviour Among Preparatory School Students in Gurage Zone, SNNPR, Ethiopia (A Cross-Sectional School Based Study)
}

\author{
Tadesse Gossaye Birru ${ }^{1}$, Mitikie Molla ${ }^{2}$, Yemane Berhane ${ }^{3}$, Amenu Wesen $^{4}$, Tesfaye Chuko ${ }^{5}$ \\ ${ }^{1}$ WHO, Global PEI, Hyderabad, Pakistan \\ ${ }^{2}$ DCH Department, Addis Ababa University, Addis Ababa, Ethiopia \\ ${ }^{3}$ Public Health Department, Addis Continental Institute of Public Health, Addis Ababa, Ethiopia \\ ${ }^{4}$ WHO, Global PEI, Freetown, Sierra Leone \\ ${ }^{5}$ Nutrition Department, UNICEF, Addis Ababa, Ethiopia
}

\section{Email address:}

gossayebirru@gmail.com (T. G. Birru),mmolla@popcouncil.org (M. Molla), yemanehberhane@yahoo.com (Y. Berhane), denegetu@gmail.com (A. Wesen), tesfaye1@gmail.com (T. Chuko)

\section{To cite this article:}

Tadesse Gossaye Birru, Mitikie Molla, Yemane Berhane, Amenu Wesen, Tesfaye Chuko. Determinants of Risky Sexual Behaviour Among Preparatory School Students in Gurage Zone, SNNPR, Ethiopia (A Cross-Sectional School Based Study). Science Journal of Public Health. Vol. 4, No. 4, 2016, pp. 330-341. doi: 10.11648/j.sjph.20160404.20

Received: May 21, 2016; Accepted: June 8, 2016; Published: July 4, 2016

\begin{abstract}
Background: There is growing evidence suggesting that young people in school are practicing risky sexual behavior. Ethiopian young people age $10-24$ years have emerged as the segments of the population most vulnerable to a broad spectrum of serious sexual health problems including STI/HIV, unwanted pregnancy and unsafe abortion. Objectives: To identify factors determining risky sexual behavior among preparatory school students. Methods: A cross-sectional quantitative study design was employed among preparatory school students in Gurage zone (SNNPR) from May to June 2009. The study participants were selected using multistage sampling. A structured self administered questionnaire was used to collect data from the participants. Results: A total of 418 participants with a response rate of $97.6 \%$ were enrolled in the study. A significant proportion of the participants $108(25.8 \%)$ were sexually initiated. About $66.6 \%$ of them were sexually active in the last one year. The overall condom use at first sexual debut was only $39.8 \%$. Out of 108 sexually active students, $58(53.7 \%)$ had had multiple sexual practice. About $62 \%$ of the participants who practiced sex had history of sexually transmitted infection. Female students who engaged in sexual practice, 17(44.7\%) encountered unwanted pregnancy and $16(94 \%)$ of them committed unsafe abortion, of which $4(25 \%)$ committed more than two abortion. Multivariate analysis showed age, poor parental attachment and substance use were significantly associated with risky sexual behavior of young students in school. Conclusion: The study has revealed that young people in preparatory schools, despite having good knowledge about their sexual health and its unwanted consequences, a significant proportion of them were found to be sexually at risk. Institutionalization of youth friendly service, condom promotion, open and regular discussion with main actor, and wide rage further studies seem to be compulsory.
\end{abstract}

Keywords: Risky Behavior, Preparatory Student, Adolescent Sexual \& Reproductive Health

\section{Introduction}

The period of adolescent is recognized increasingly both as an important determinants of future health and as a especially vulnerable period of life. The concern of sexual risk taking as well as the fact that young people aged $15-24$ years constitute about 20 percent of the sub- Saharan African population and will therefore, have a substantial importance in understanding the pattern of their sexual behavior [1]

Most young people are exposed to risky behavioral practices in their teens. Moreover, because they practice risky behaviors without precautions, they are exposed to various 
SRH problems, including STIS and HIV/AIDS. In addition the well-being of females is jeopardized by unwanted teenage pregnancy and its untoward consequences. Globally young people account for half of all new cases of HIV infection. For this reason young people around the world have been termed the "AIDS generation" $[1,2,3]$

Young people throughout the world and particularly those in developing countries have been exposed to these health risks as they have inadequate information, knowledge or guidance about STIs, HIV/AIDS, SRH and related problems. They have limited access to health services, or there are no health facilities that have been arranged for them to solve the problems they face. In addition, comprehensive national youth SRH policies and strategies that specifically address and meet young people's sexual needs are scarce and relatively uncommon in most countries [3].

As a result, in many settings young people have few places to look for accurate information and sound guidance, counseling and treatment on sexual problems including, HIV/AIDS and STIs. The problem that young people currently face warrant meaningful consideration. Ethiopian young people have problems similar to young people elsewhere. Although they have profound reproductive health needs, these have been neglected for many years [4, 5].

Adolescents have not traditionally been considered a health priority, since they have lower morbidity and mortality than older and younger age groups and their needs of sexual health information and services have not been recognized [5, 6]. Some studies and assessments carried out in recent years in different parts of the country have indicated that Ethiopian young people (aged 10-24) have emerged as the segment of the population most susceptible to a broad spectrum of serious sexual health problems including STI and HIV/AIDS infections, unwanted pregnancies and unsafe abortion. Knowledge of other STIs is much more limited than that of HIV. And STI is useful marker for unprotected sex and also a co-factor for HIV transmission. Sexually active girls ages 1519 are three times more likely to report STI than sexually active boys in the same age group. Thus young girls are at increased risk of encountering STI, as probably engaged in unprotected sex due to the limited control they may have over their sexual lives [6, 7]. Some recent assessments indicate that the major problems of Ethiopian youth are related to lack of SRH services designed for them. That is, there is scarcity of special program on their sexual matter, HIV/AIDS prevention and treatment services, whether integrated with the existing health facilities or free standing and ideally providing basic services and reliable information to young people in affordable, confidential and youth friendly environment. The existing public health programs and services cater to a wider range of age groups, and have limited coverage of young people [7].

However, except for a few studies that have been conducted in specific areas, there is lack of systematically collected information on young people's knowledge, needs and utilization of sexual health services. Furthermore, rigorous assessment has not been under taken so far to identify whether special and youth-friendly $\mathrm{SRH}$ and HIV/AIDS prevention and treatment services exist in the country for young people, or how far the services that are provided meet the needs of the young people. The opening of preparatory and technical schools in Ethiopia has become necessary for students particularly the rural areas to move to the nearby towns for the duration of their training. Adolescents who come from rural areas (who might lack consistent adult supervision and exposed to a relatively new environment) are having an elevated sexual risk taking behavior. Therefore this study is aimed at identifying risky sexual behavior and their determining factors and how wide spread they are among students in preparatory schools.

\section{Literature Review}

As part of the larger social system, a number of factors affect adolescents' attitude and behavior. The field of adolescent health has focused on those risk factors that predispose adolescents to health and social problems such as HIV/STI acquisition, early sexual initiation, unwanted pregnancy, unsafe abortion, substance abuse and other related practices leading to unwanted outcome of behaviors. In many countries where HIV prevalence is high, young people become more vulnerable and are potentially at risk $[8,9,10]$.

Most people initiate sexual activity during adolescent. As the study made in eleven countries across the globe, the highest prevalence in premarital sexual initiation was found in sub-Saharan Africa. More than half of all adolescents aged 15-19 years are sexually experienced. The age of starting sexual intercourse is heavily dependent on local cultural sanctions and is often very different for males and females. Much of this activity is risky and contraceptive use is often erratic or inconsistent, so unwanted pregnancy and unsafe abortions are observed in many settings. Studies have revealed high level of knowledge about the transmission of HIV among young people with a paradoxically high level of risky activity. Various studies indicated that, large percentages of sexually active youth have engaged in sexual intercourse with more than one partner $[10,11]$.

Condon use is a key means of preventing risky sexual behavior. Although data from sub-Saharan Africa and the developed suggests that use of condom by adolescent is increasing worldwide, the proportion of sexually active young people who report condom use at most recent sex is clearly, too low to prevent the spread of STIs. WHO estimated that 340 million new cases of curable STIs - syphilis, gonorrhea, and trichomoniasis occur every year. Young people are the most affected group in the population. The largest number of new infections occurred in south and south East Asia, followed by sub-Saharan Africa. The dangers of sexually transmitted infection; HIV, unwanted pregnancy, and abortion are higher $[12,13]$. Of the estimated 333 million new STDs that occur in the world every year, at least one-third occur in young people under 25 year of age. According to WHO estimates, 1 in 20 adolescents worldwide acquires an STD each year. Studies conducted both in develop and developing countries have 
confirmed that STDs are a major public health problem, but in sub-Saharan Africa the incidence rates are far higher. The prevalence of STDs in Ethiopia is the highest in Africa. Globally, in the past 20 years, more than 6 million people have been infected with HIV, half of whom became infected between the age 15 and 24 years [14, 15].

The biological susceptibility of the less mature sexual structure at their very young age aggravates and /or leads to devastating out come. These teenagers are tomorrow's parent. The reproductive sexual health decisions these young people make today will affect the health and the wellbeing of their countries and of their world for decades to come [16]

The Ethiopian Behavioral surveillance survey reported a $5 \%$ reported STI among out of school youth. Other studies indicate a reported prevalence of $2-3 \%$ of STI among the youth 15-24 years in different parts of the country $[17,18]$. Different behavioral studies conducted among urban youth indicated that about $33-49 \%$ of male $6-10 \%$ of female adolescents were sexually active with mean age at first sexual debut of 11-17 years for both sex. 19: 13-59.

A study conducted among students of Gondar College of Medical Sciences showed that among the sexually active, $7.8 \%$ had sex with commercial sex workers. The same study documented condom use rate in the last sexual encounter was $37.1 \%$, and consistent condom use rate was only $6.4 \%$ [20].

Another study under taken among high school students, from two large towns in Amhara region showed, the mean age of sexual initiation was $15.5(\mathrm{SD}=2.3)$ years were boys having their debut slightly earlier than girls. By age 17 years, more than $80 \%$ of students had at least one penetrative sexual encounter. Although most sexual initiation took place among peers, about $20 \%$ of first sexual encounters were with older, casual or commercial sex partners and only $40 \%$ of first sexual encounter were protected against STIs [21]

Factors such as peer pressure, lack of maturity, and alcohol and drug use put pre-college and college students at risk for STI, HIV infection. College students may have unprotected sex while under the influence of alcohol or other drugs, which they ordinarily might not do. Abandoning safer sex techniques, failing to use condoms correctly and consistently, and having sex while under the influence can lead to possible infection with HIV or other sexually transmitted diseases. [22].

School adolescent and young adults who use drugs and alcohol often take risks that endanger their health and the health of others. One of the most harmful risks is that of engaging in risky sexual activities. Few studies has demonstrated that the use of alcohol and drug is related to the occurrence of unsafe sexual behavior that places school adolescents at risk of pregnancy or contracting sexual transmitted diseases [23].

\section{Objective of the Study}

\subsection{General Objective}

To identify factors determining risky sexual behaviors among students in preparatory school.

\subsection{Specific Objectives}

(1) To assess the level of sexual knowledge, attitude and behavior

(2) To identify determinant factors to the risky sexual behavior among school adolescents

\section{Methodology}

\subsection{Study Design and Area}

A cross-sectional study design was employed between May to June/2009 in five randomly selected preparatory school students found in Gurage Zone of Southern Nations, Nationalities and People's Region state. The total population of the Zone was 1,770,111; and has 13 Woredas and 2 town administrations. The Zone capital (wolkite) is located $160 \mathrm{~km}$ South West of Addis Ababa and $432 \mathrm{~km}$ North from the regional capital (Hawassa).

\subsection{Source Population}

The source populations were both male and female students currently attending preparatory schools in Gurage Zone, SNNPR. The sizes of the source population enrolled in preparatory schools for academic year 2009 were about 5051 $($ Male $=3243$ and Female $=1807)$ making a sex ratio of $1: 1.8$.

\subsection{Sample Size}

The sample size was estimated using a single population proportion. A Prevalence level that estimate maximum sample size (50\%), marginal error (0.05), with $95 \%$ confidence interval and alpha (0.05). $\mathrm{n}=\mathrm{Z} 2 \mathrm{pq} / \mathrm{d} 2$ for population greater than ten thousand. But for small population, less than ten thousand or in this case 5051; adjusted sample size, where: $\alpha=0.05, \mathrm{z}=1.96$ at $95 \% \mathrm{CI}$, $\mathrm{p}=50 \%, \mathrm{q}=1-\mathrm{p}, \mathrm{d}=$ degree of precision $=0.05$ is equals to $\mathrm{n} / 1+\mathrm{f}$, Where $\mathrm{f}=\mathrm{n} / \mathrm{N}$. By substituting: $\mathrm{n}=1.962(.5)(.5)=$ 384 , hence adjusted sample size $(n)=384 / 1+384 / 5051=357$ (plus 20\% none response rate) $=428$

\subsection{Sampling Strategies}

A multistage sampling technique was employed. Out of the five existing preparatory schools in the study area, classes of the respective schools were randomly selected. Then, the participants were selected randomly using a systematic random sampling technique for each school proportionate to size. Separate lists of male and female students were used to avoid bias that arises as a result of periodic or cyclical sequence in the list. The sampling interval or the sampling fraction was obtained by dividing the number of units in the population by the desired sample size of the respective school and class room. 
Table 1. List of randomly selected preparatory schools and sample proportional to size Gurage Zone, May 2009.

\begin{tabular}{|c|c|c|c|c|c|c|}
\hline \multirow{2}{*}{$\begin{array}{l}\text { List of Five randomly selected } \\
\text { preparatory Schools in the zone }\end{array}$} & \multicolumn{3}{|c|}{ Total preparatory Students by school } & \multicolumn{2}{|c|}{ Sample by sex Proportional to size } & \multirow{2}{*}{$\begin{array}{l}\text { Total sample size/both sex } \\
\text { /for selected Schools. }\end{array}$} \\
\hline & Male & Female & Total & Male & Female & \\
\hline Wolkite preparatory school & 771 & 219 & 990 & 69 & 36 & 106 \\
\hline Imdiber Preparatory school & 447 & 118 & 565 & 40 & 20 & 61 \\
\hline Agena Preparatory school & 339 & 116 & 455 & 31 & 20 & 50 \\
\hline Butajira preparatory school & 1027 & 318 & 1345 & 91 & 53 & 146 \\
\hline Buee preparatory school & 505 & 136 & 641 & 45 & 23 & 69 \\
\hline
\end{tabular}

\subsection{Data Collection}

Data were collected using a standard structured questionnaire, first developed in English and then translated into Amharic. The questionnaire comprises of 4 parts. Part one: the socio-demographic characteristic; Part two: questions on knowledge, attitude and sexual behavior of participants; Part three: questions of reproductive health needs and related problems, and Part four: question on participant's service utilization and gaps.

\subsection{Data Quality}

Three data collectors and a supervisor were recruited from health facilities, who have a college diploma and were research oriented. The data collectors were trained on the data collection tool and procedures by the researcher. The structured questionnaire was pre-tested in a different before the commencement of the actual data collection. The questionnaire was assessed for its consistency, clarity, understandability, completeness, reliability and adherence to the objective of the study. Then the questionnaire was self administered by the data collectors after consent is assured. The participants were instructed to fill the questionnaire without writing their name. Instruction was given to fill the questionnaire honestly.

\subsection{Data Analysis}

Data were cleaned (checked for errors, impossible, implausible and inconsistent values, edited and post coded for computerization), then entered in to a computer and analyzed using EPI info and SPSS. Descriptive statistics, measures of associations and statistical tests for significance were carried out where ever appropriate at the level of $5 \%$. The findings were presented using tables and figures. For the knowledge questions each close ended question has got 1 point if the response was correct and 0 if the response was not correct. Correct answers scored above 70\% were considered as good knowledge and below that poor knowledge. Attitude questions had two options, agree and disagree. Any responses other than the two options were included as disagree. After recording has been made, those who answered the desired answer, were considered as having a positive attitude and those who answered the undesired answer were considered as having a negative response. All positive responses were given point 1 and the negative one's 0 . Participants who scored above $60 \%$ were considered to have a positive attitude and those who scored below $60 \%$ were labeled as to have a negative attitude.

\subsection{Study Variables (Independent Variables and Dependent Variables)}

\subsubsection{Independent Variables}

Age, Sex, Residence, Marital status, Religion, ethnicity, Parental education, parental attachment, substance use.

\subsubsection{Dependent Variables}

STIs/HIV, Unwanted pregnancy, unsafe abortion, multiple sex, and no condom use

\subsection{Operational Definition}

Preparatory school: The type of school where by receiving students who have successfully passed grade 10 and prepare them for higher education (college or University). It is synonymous with the former grade 11 and 12 .

Substance use: consumption of any stimulating and addictive substances like khat, alcohol, drugs and other similar things favoring for untoward sexual practices.

Risky sexual behavior: a student having any one of the following: No consistent condom uses, have multiple sexual partner, had history of STI, had history of unwanted pregnancy, and history of abortion.

Multiple sexual practices: two or more sexual intercourse with different partners.

Forced sex: the practice of doing sex without the will of the counterpart (female)

Living alone: living away from parents/care takers or relatives usually in a rented house to attend preparatory schooling.

Graduate: parental educational status holding either diploma, degree or both.

Out of school sex: sex committed with any person, male or female other than students in school and commercial sex workers.

Good knowledge: category of responses if the study participants answered knowledge questions above or equal to $70 \%$ correctly. And less than that is considered as poor.

Literate: Able to read and write from the lower grade level to the higher graduate level

\subsection{Ethical Consideration}

Ethical clearance was obtained from the Joint MPH 
program University of Gondar and Addis continental Institute of Public Health and the local government. Informed verbal consent was also obtained or secured from the study participant prior to the administration of the questionnaire, and confidentialities were strictly kept.

In the mean time students with any sexual health problems were informed to visit health facility or consult health professions for help.

\section{Result}

\subsection{Back Ground Characteristics}

A total of 418 participants, with a response rate of $97.6 \%$ were enrolled in the study. About 271(64.8\%) of the participants were male and $147(35.2 \%)$ were females, giving a sex ratio of $1: 1.8$. About 204(48.8\%) were from urban and $214(51.2 \%)$ from rural. Large proportion of the participants were single $334(79.9 \%), 45(10.8 \%)$ have boy or girl friend and $37(8.9 \%)$ were married. Three fourth $316(75 \%)$ of the participants were from Gurage by ethnicity followed by Amhara 62(14.8\%) and others 40(9.2). The majority of the participants 260(62.2\%) were Orthodox Christian by religion followed by Muslim 104(24.9\%) and other Christian 54(12.9). About 384(91.8\%) of the study participants' age were distribution between 15-19 years, with the mean age of 18.3 years and standard deviation $+/-1.64$ (Figure 4 ).

About $183(43.8 \%)$ of the participants were first year or grade 11 students, and about $235(56.2 \%)$ were second year or grade 12. About half of respondents' mothers 209(50\%) and $119(28.5 \%)$ fathers were illiterate (not able to read and write) and the remaining $50 \%$ of mothers and $71.5 \%$ of participants' father were literate (from the lower grade level to the graduate level). About 162(38.8\%) were living with either of their parents, while $113(22 \%)$ living with their friends and relatives and $125(29.4 \%)$ living alone in a rental house to attend preparatory schooling (Table 2).

Table 2. Socio-demographic characteristics of preparatory students in Gurage zone May 3009.

\begin{tabular}{lll}
\hline Background characteristics $\mathbf{n}=\mathbf{4 1 8}$ & Frequency & Percent $\mathbf{( \% )}$ \\
\hline Sex & & \\
Male & 271 & 64.8 \\
Female & 147 & 35.2 \\
Age & & \\
$15-19$ & 384 & 91.9 \\
20-24 & 34 & 8.23 \\
Residence & & \\
Urban & 204 & 48.8 \\
Rural & 214 & 51.2 \\
Religion & & \\
Orthodox & 260 & 62.2 \\
Muslim & 104 & 24.9 \\
Other Christians & 54 & 12.9 \\
Ethnicity & & \\
Gurage & 316 & 75.6 \\
Amhara & 62 & 14.8 \\
Others & 40 & 9.2 \\
Marital Status & & \\
\hline
\end{tabular}

\begin{tabular}{lll}
\hline Background characteristics $\mathbf{n}=\mathbf{4 1 8}$ & Frequency & Percent (\%) \\
\hline Single & 334 & 79.9 \\
Married & 37 & 8.9 \\
Others & 47 & 9.2 \\
Educational status & & \\
Grade 11 (year one) & 183 & 43.8 \\
Grade two (Year two) & 235 & 56.2 \\
Parental status & & \\
Both are alive & 291 & 69.6 \\
Only father is alive & 24 & 5.7 \\
Only mother is alive & 52 & 12.4 \\
Both are not alive & 51 & 12.2 \\
Respondents currently living with & & \\
Either father or mother & 162 & 38.8 \\
Relatives & 42 & 10 \\
Friends & 91 & 21.8 \\
Alone & 125 & 29.4 \\
Father's Educational level & & \\
Illiterate & 119 & 28.5 \\
Grade 1-8 & 176 & 59.2 \\
Grade 9-12 & 41 & 9.8 \\
Graduate & 52 & 12.8 \\
Mother's Educational level & & \\
Illiterate & 209 & 50 \\
Grade 1-8 & 153 & 36.6 \\
Grade 9-12 & 33 & 7.9 \\
Graduate & 23 & 5.5 \\
\hline & & \\
\hline
\end{tabular}

\subsection{Knowledge of the Participants About Risky Sexual Behavior}

The study has revealed the overall knowledge of the participants was high. About 417(99.8) were heard about STI and HIV, about 408(97.6\%) and 313(74.9) of the participants knew as HIV/AIDS is sexually transmitted and incurable disease respectively. Out of the total participants who have heard about VCT, 406(97.1\%) reported VCT as an entry point for the prevention of HIV/AIDS transmission. About $79 \%$ of the study participants have good knowledge (Figure 1).

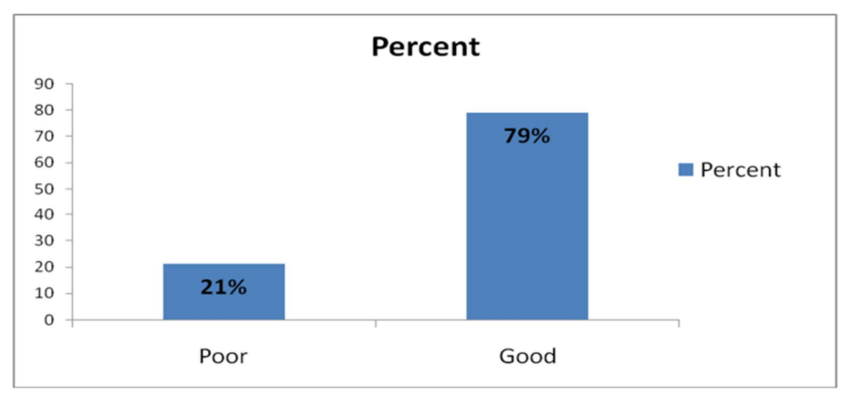

Figure 1. The overall level of the participants' knowledge about their risky Sexual behavior, Gurage zone May, 2009.

About 104(24.4\%) didn't know where to get VCT service and $136(32.5 \%)$ of the respondents answered as condom doesn't protect from transmission of AIDS. About 232(55.5\%) mentioned as they have heard about ART and of which 148(63) responded as ART is useful to prolong the life of HIV positive individuals and the remaining $84(36.2 \%)$ failed to know what it mean (Table 3). 
Table 3. Knowledge of preparatory students about risky sexual behavior, in Gurage Zone May 2009.

\begin{tabular}{lll}
\hline Knowledge questions n=418 & Yes \#(\%) & No\#(\%) \\
\hline Heard about STI/HIV & $417(99.8)$ & $1(.2)$ \\
HIV/AIDS is sexually transmitted disease & $408(97.6)$ & $10(2.4)$ \\
HIV/AIDS is curable disease & $105(25.1)$ & $31(74.9)$ \\
A healthy looking person could have HIV & $316(75)$ & $112(25)$ \\
Condom protects from STI/HIV & $282(67.5)$ & $136(32 . \%)$ \\
Heard about VCT & $411(98.3)$ & $7(1.70)$ \\
VCT prevents transmission of HIV & $406(97.1)$ & $12(2.9)$ \\
Hospitals are the only place for VCT service & $104(24.4)$ & $314(75.6)$ \\
$\begin{array}{l}\text { Heard about ART } \\
\text { Can mention the most existing sexual }\end{array}$ & $232(55.5)$ & $186(44.5)$ \\
$\begin{array}{l}\text { H/problems } \\
\text { A single episodes of unprotected sex can cause }\end{array}$ & $408(97.8)$ & $10(2.4)$ \\
$\begin{array}{l}\text { HIV } \\
\begin{array}{l}\text { Early sexual initiation can lead to sexual } \\
\text { problems }\end{array}\end{array}$ & $302(72.2)$ & $116(27.8)$ \\
\hline
\end{tabular}

\subsection{Attitude of the Respondents About Their Sexual Behavior}

The study found out that, about $285(68 \%)$ of the respondents believed or agree that a person with STD is highly likely to have HIV/AIDS. A large proportion of the respondents 395(94.5\%) disagree that, students are looking too young, so that they couldn't have any sexually transmitted diseases including HIV/ AIDS. On the other hand, about $322(77 \%$ ) believe that sign and symptoms of sexually transmitted diseases could occur without having any sexual intercourse, quite significant number of participants $(56 \%)$ believe that teenagers couldn't get pregnant at the first penetrative intercourse even if the partners use condom. Generally, about 284(68\%) of the respondents have responded the desired answer and hence have a positive attitude and the remaining 134(32\%) responded none desired answer and found to have a negative attitude (Table 4).

Table 4. Attitude of participants about their sexual behavior, Gurage zone May, 2009.

\begin{tabular}{|c|c|c|c|c|}
\hline \multirow{2}{*}{ Statement questions on attitude $n=418$} & \multicolumn{2}{|c|}{ Agree } & \multicolumn{2}{|c|}{ Disagree } \\
\hline & M & $\mathbf{F}$ & M & $\mathbf{F}$ \\
\hline I believe a person with STD is high risk to acquire HIV/AIDS & 189 & 96 & 82 & 51 \\
\hline As students are too young, they couldn't have any sexually transmitted diseases or HIV/AIDS & 16 & 7 & 255 & 140 \\
\hline I believe abstaining from sex is better than using condom to prevent STI, HIV/AIDS and unwanted pregnancy & 83 & 42 & 188 & 105 \\
\hline Sign and Symptoms of STI could occur without having any sexual intercourse with anyone & 210 & 112 & 61 & 35 \\
\hline I believe regular use of condom protects from risky sexual behavior to happen. & 20 & 19 & 251 & 128 \\
\hline Use of condom decreases sexual pleasure (not willing to use) & 16 & 9 & 255 & 138 \\
\hline Teenagers couldn't get pregnant at the first penetrative intercourse even if the partners use condom & 148 & 88 & 123 & 59 \\
\hline Early disclose of sexual problems could prevent untoward consequences and complications & 110 & 56 & 161 & 91 \\
\hline
\end{tabular}

\subsection{Practice Related to Participants' Sexual and Reproductive Health Needs}

About $108(25.8 \%)$ of the total participants reported as they had had sexual intercourse in their life time and out of whom about $72(66.7 \%)$ were sexually active during the last one year. The overall condom use at first sexual debut was only
$43(39.8 \%)$. Out of 108 sexually practiced in their life time, $58(53.7 \%)$ have committed multiple sexual practice. Out of those who committed multiple sexual intercourse, 26(24\%) reported persistent condom use. Out of 70 male students who had sexual practiced before, about $20(28.6 \%)$ of them had sexual intercourse with commercial sex workers in their life time. And only 11(83\%) used condom regularly (Figure 2).

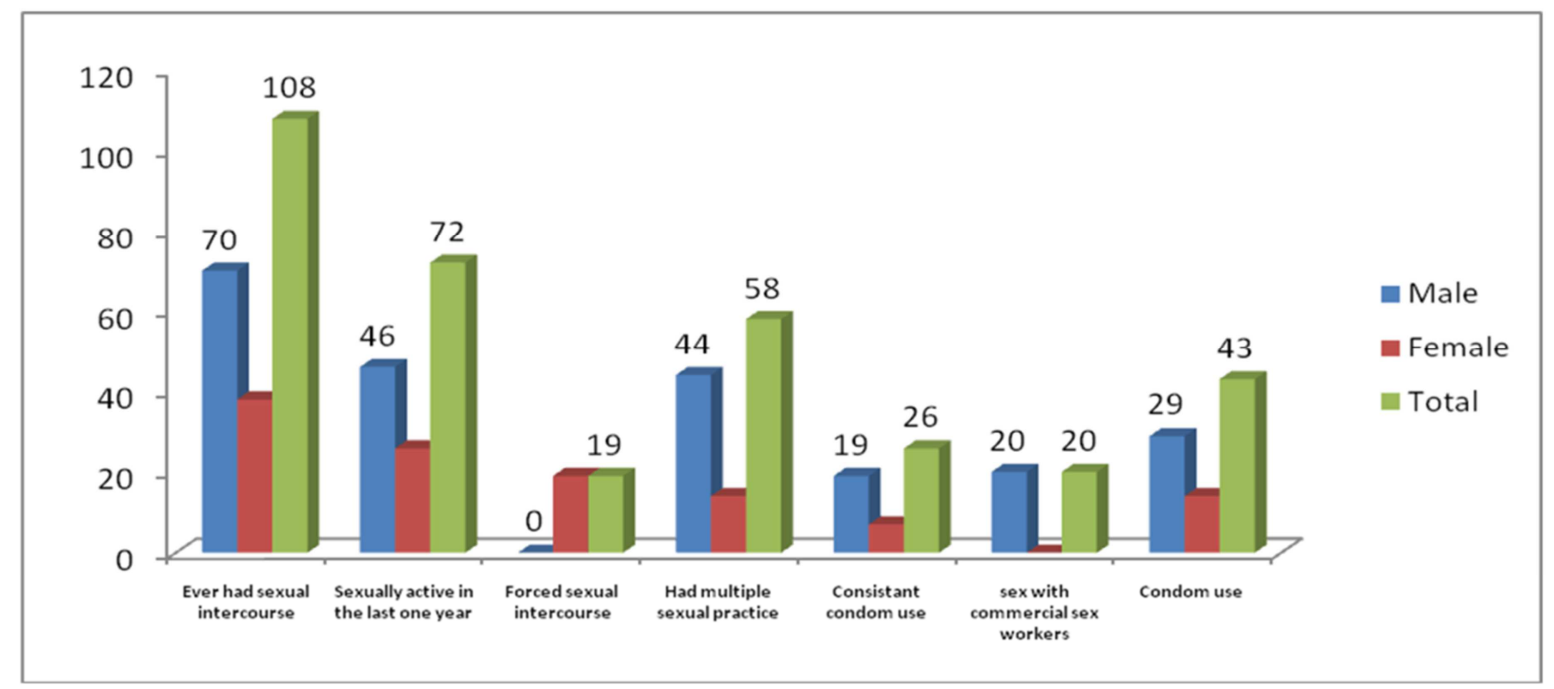

Figure 2. Present sexual behavior of participants by sex, Gurage zone May, 2009. 
About $92(85.2 \%)$ of the participants who practiced unprotected sex had history of sexually transmitted diseases and of whom only $71.6 \%$ had treated by the time they had the symptom. Out of 38 female students who ever had sexual intercourse, 17(44.7\%) encountered unwanted pregnancy and $16(94 \%)$ of them committed abortion and of which $4(25 \%)$ experienced two and more abortion. About 53(75.2\%) of sexually active male and $3.9 \%$ of female students were reported as they were using substances like khat, alcohol and drugs. Five percent of the male students use alcohol for sexual arousal (Table 5).

Table 5. Sexual practice of the study participants Gurage zone May, 2009.

\begin{tabular}{|c|c|c|c|}
\hline \multirow{2}{*}{ Sexual practice } & Male & Female & Total \\
\hline & $n=70$ & $n=38$ & $n=108$ \\
\hline Had history of STI & $60(85.7)$ & $32(84.2)$ & $92(85.2)$ \\
\hline Treated for STI & $27(38.7)$ & $21(55.3)$ & $48(44.4)$ \\
\hline Had history of unwanted pregnancy & -- & $17(44.7)$ & $17(44.7)$ \\
\hline Had history of unsafe abortion & -- & $16(94)$ & $16(94)$ \\
\hline Substance use & $53(75.2)$ & $3(7.9)$ & $56(51.9)$ \\
\hline Substance use for sexual arousal & $5(13.15)$ & 0 & $5(13.15)$ \\
\hline
\end{tabular}

The mean age of the study participants was 18.3 years (18.56 for male and 17.83 for female) with standard deviation 1.64 . The minimum age at first sex was 16. The mean age at first sex was 16.4 years, 16.5 for male and 16.2 for female (Figure 3 ).

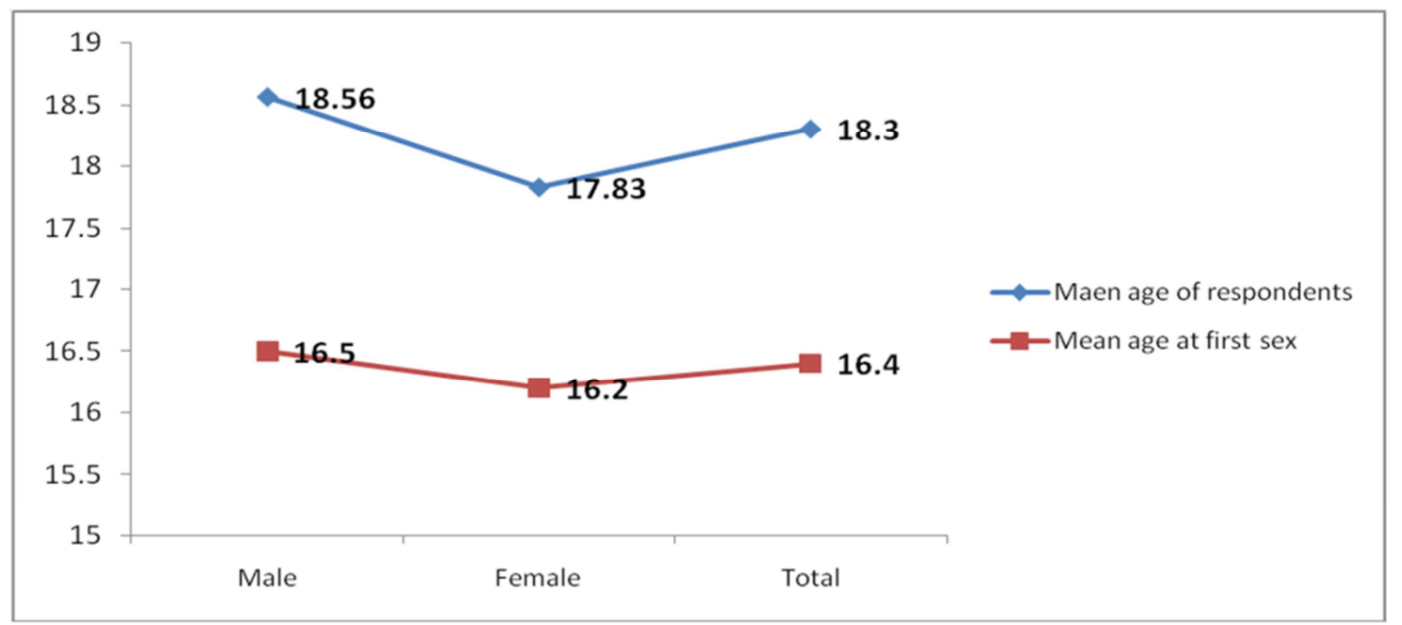

Figure 3. Mean age of preparatory students versus mean age at first sex, Gurage zone May, 2009.

The study had also revealed that $39(36 \%)$ of the respondent's sexual initiation at first sexual debut was intentional, $35(32.4 \%)$ were not able to justify the reason for the initiation, $24(22.2 \%)$ were forced, and followed by $5(4.6 \%)$ to get marry and 5 more for exchange of benefit or money (Figure 4).

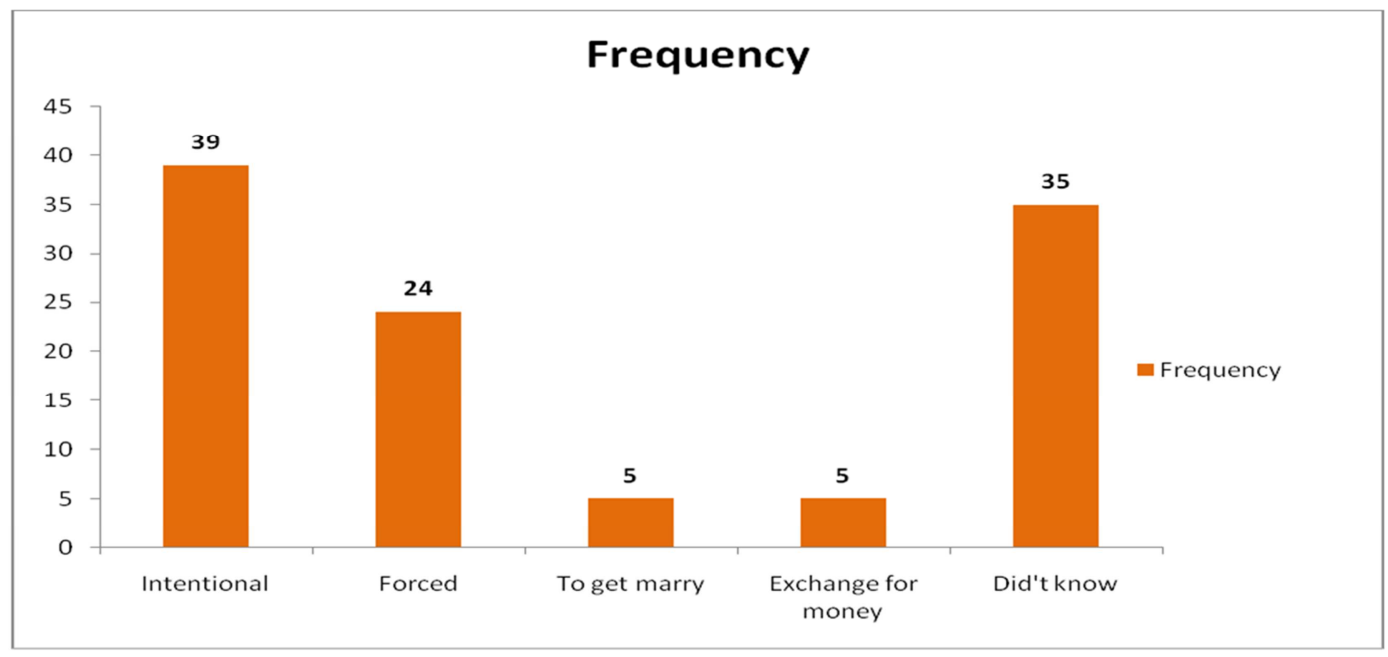

Figure 4. Reason for participants' initiation at first sexual intercourse, Gurage zone, May, 2009. 
A total of $47(43.5 \%)$ of the sexually active participants made sexual intercourse with only one partners in their life time. And about 28(26\%) had sexual practice with two partners and 15(30.5\%) had sexual intercourse greater than two partners (Figure 5).

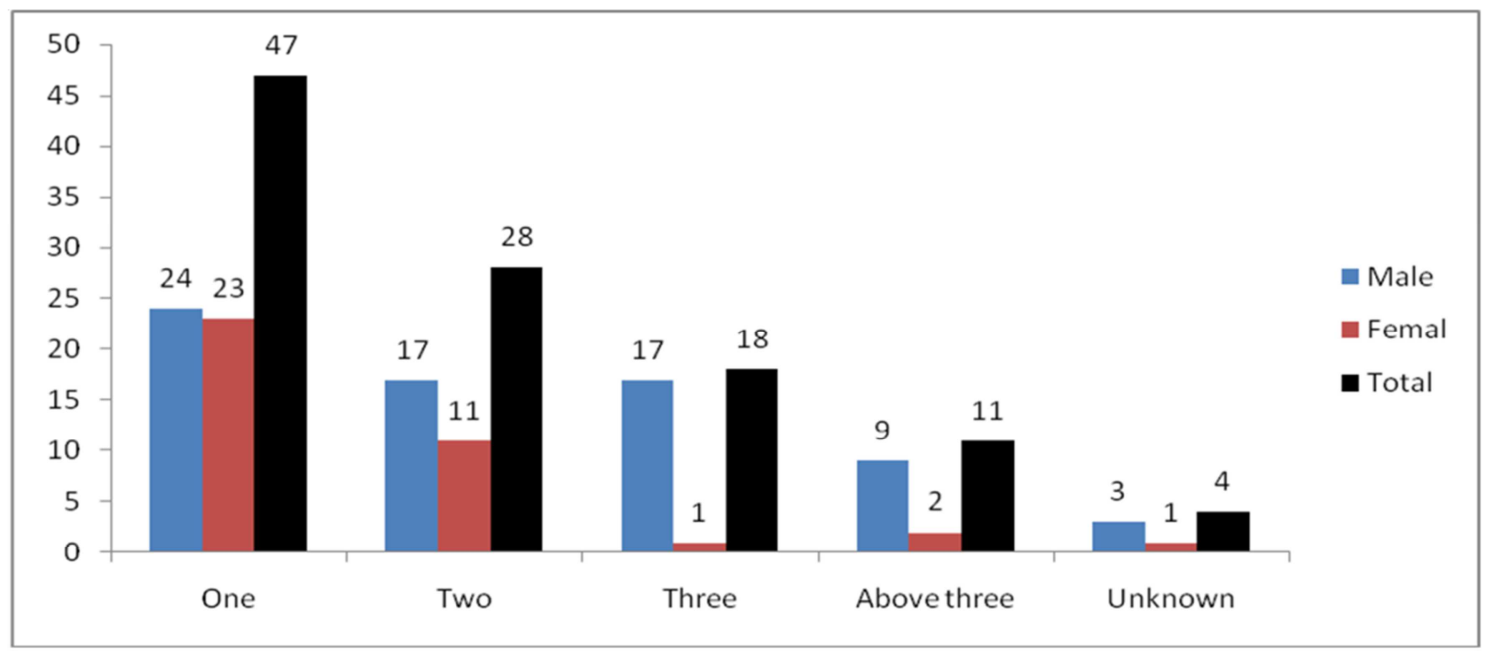

Figure 5. Number of sexual partners reported by respondents, Gurage zone, 2009 ( $n=108)$.

A total of 191(45.7\%) have been tested for HIV. Out of the total tested, 126(65.9\%) were male and 65(34\%) females. The remaining 227(54.3\%) didn't get tested. The reason for not testing for HIV was many. The majority of the respondents were reported fear of positive result as a reason for not testing $(22.1 \%$ male and $17 \%$ of females) followed by the service was not available (11.8\% for male and $10.8 \%$ for females- figure 6.

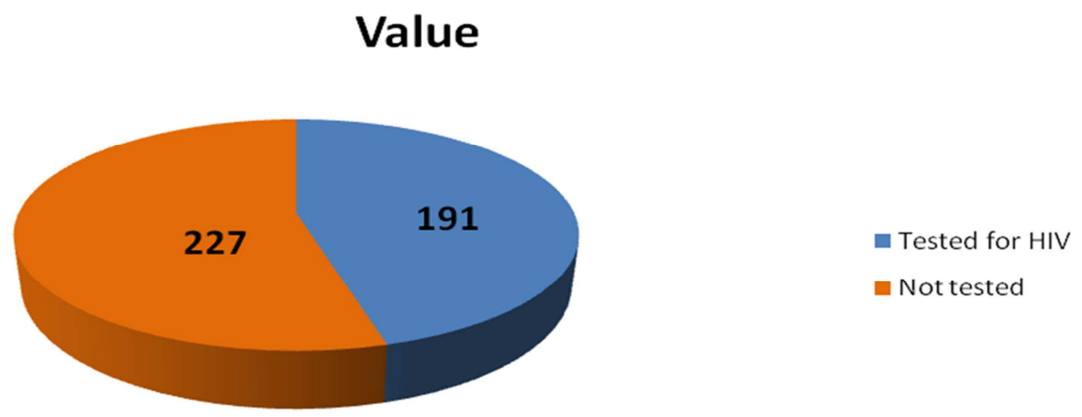

Figure 6. The proportion of student's tested for HIV/AIDS, Gurage zone May 2009.

Table 6. Participants' Justification for not testing or using Voluntary Counseling and Testing (VCT), in Gurage zone, May 2009.

\begin{tabular}{|c|c|c|c|}
\hline \multirow{2}{*}{ Justification } & Male (\# \%) & Female (\# \%) & Total (\#\%) \\
\hline & $\mathbf{n}=\mathbf{2 7 1}$ & $\mathrm{n}=147$ & $n=418$ \\
\hline I Have no HIV/AIDs & $24(8.9)$ & $34(8.1)$ & $58(13.9)$ \\
\hline I haven't thought of it & $17(6.3)$ & $11(7.5)$ & $28(6.7)$ \\
\hline Fear of positive result & $60(22.1)$ & $25(17)$ & $85(20.3)$ \\
\hline The service is not available & $32(11.8)$ & $16(10.8)$ & $48(11.5)$ \\
\hline Fear of stigma and discrimination & $25(9.2)$ & $17(11.6)$ & $42(10)$ \\
\hline I lose hope & $29(10.7)$ & $17(11.6)$ & $46(11)$ \\
\hline Has no benefit for student & $16(5.79)$ & $7(4.8)$ & $23(5.5)$ \\
\hline The test is not reliable & $19(7)$ & $9(6.1)$ & $28(6.7)$ \\
\hline Fear of confidentiality & $4(1.5)$ & $6(4)$ & $10(2.4)$ \\
\hline I trust my partner & $10(3.7)$ & $6(4)$ & $16(3.8)$ \\
\hline I didn't commit risky sexual intercourse & $20(7.4)$ & $17(11.5)$ & $37(8.85)$ \\
\hline I don't really justify why I didn’t & $15(5.5)$ & $6(4)$ & $21(7.74)$ \\
\hline
\end{tabular}

Most of the male students $41.4 \%$ used to practice their first sexual intercourse with, out of school persons followed by $28.6 \%$ with commercial sex workers and $25.7 \%$ with school friends. On the other hand $39.5 \%$ of female respondents reported as they had their first or penetrative sex with school friends, $36.8 \%$ with, out of school persons and $18.4 \%$ with their teachers (Figure 7 and 8). 


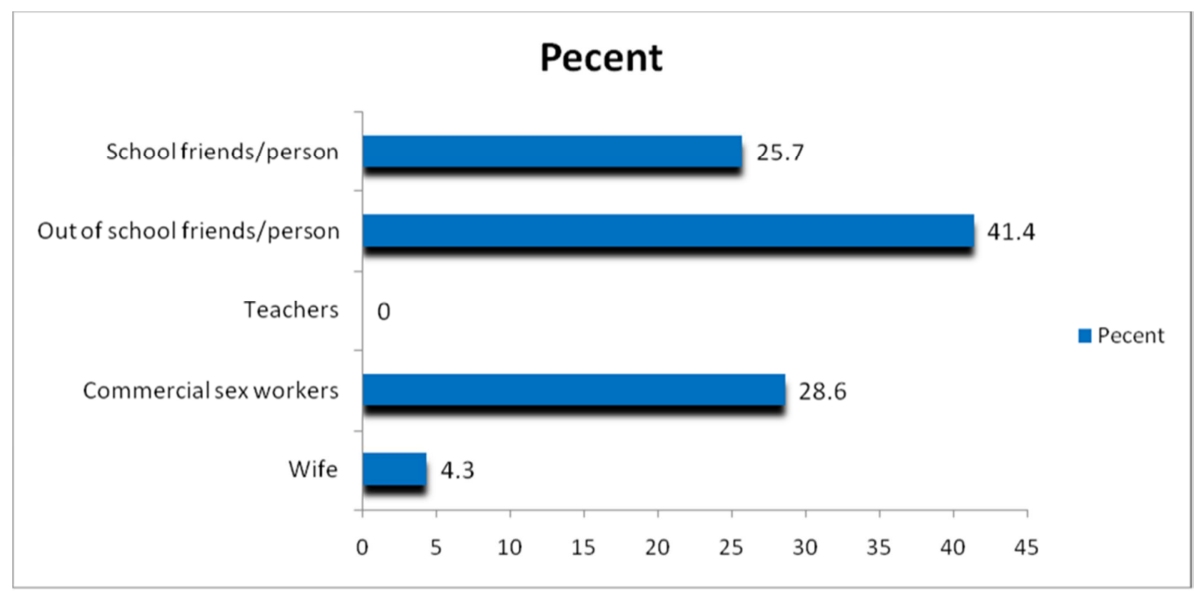

Figure 7. Male students' first sexual partner in Gurage Zone preparatory schools May 2009.

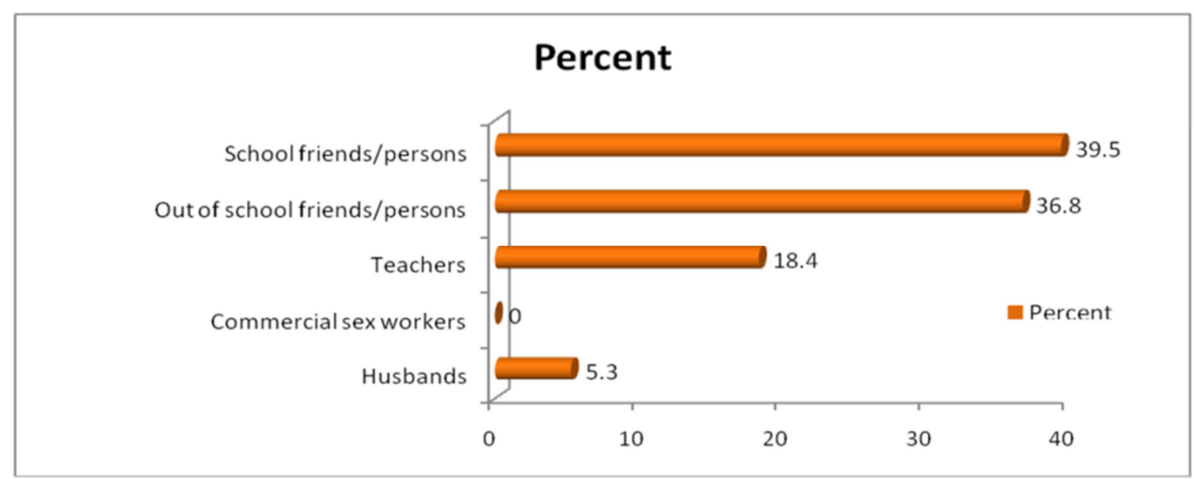

Figure 8. Female students' first sexual partner, in Gurage zone preparatory school May 2009.

A multivariate analysis showed, age, condom and substance use were statistically significant with adj. OR, 95\% CI $2.889(1.720,4.887), 0.470(0.285,0.775)$ and $0.302(0.170,0.538)$ respectively.

Table 7. Factors affecting risk sexual behavior among preparatory school students Gurage zone, May 2009.

\begin{tabular}{|c|c|c|c|c|}
\hline \multirow{2}{*}{ Variables } & \multicolumn{4}{|c|}{ Risky sexual behavior } \\
\hline & Yes $=112$ & No $=306$ & Crude OR (95\% CI) & Adj. OR (95\% CI) \\
\hline \multicolumn{5}{|l|}{ Age } \\
\hline $15-19$ & $78(22.7)$ & $266(77.3)$ & $2.899(1.720,4.887)$ & $2.899(1.720,4.887)^{*}$ \\
\hline$\geq 20$ & $34(45.9)$ & & $40(54.1)$ & \\
\hline \multicolumn{5}{|l|}{ Sex } \\
\hline Male & $71(26.1)$ & $200(73.8)$ & $1.090(0.694,1.70)$ & $1.090(0.694,1.710)$ \\
\hline Female & $41(27.9)$ & $106(72.1)$ & & \\
\hline \multicolumn{5}{|l|}{ Residence (now) } \\
\hline Urban & $58(28.6)$ & $145(71.4)$ & $0.839(0.544,1.293)$ & $0.839(0.544,1.293)$ \\
\hline Rural & $54(25.1)$ & $161(74.9)$ & & \\
\hline \multicolumn{5}{|l|}{ Parental attachment } \\
\hline Live with Parents & $47(29)$ & $115(71)$ & $0.833(0.536,1.294)$ & $0.833(0.536,1.294)$ \\
\hline Live alone/others & $65(25.4)$ & $191(74.6)$ & & \\
\hline \multicolumn{5}{|l|}{ Condom use } \\
\hline Yes & $34(39.5)$ & $52(60.5)$ & $0.470(0.285,0.775)$ & $0.470(0.285,0.775)^{*}$ \\
\hline No & $78(23.5)$ & $254(76.5)$ & & \\
\hline \multicolumn{5}{|l|}{ Marital status } \\
\hline Single & $13(100)$ & $24(64.7)$ & $0.648(0.318,1.322)$ & $0.648(0.318,1.322)$ \\
\hline Married & $99(26)$ & $282(74)$ & & \\
\hline \multicolumn{5}{|l|}{ Religion } \\
\hline All Christian & $69(26.5)$ & $191(73.5)$ & $1.035(0.663,1.616)$ & $1.035(0.663,1.616)$ \\
\hline Muslim & $43(27.2)$ & $115(72.8)$ & & \\
\hline \multicolumn{5}{|l|}{ Substance use } \\
\hline Yes & $28(50)$ & $28(50$ & $0.302(0.170,0.539)$ & $0.302(0.170,0.538)^{*}$ \\
\hline No & $84(23.2)$ & $278(76.8)$ & & \\
\hline
\end{tabular}

* Significant 
Sexual initiation was associated with the variable age and poor parental attachment (living alone while attending preparatory schooling).

Table 8. Determinants of sexual initiation among preparatory school students in Gurage Zone, SNNPR, May 2009.

\begin{tabular}{|c|c|c|c|c|}
\hline \multirow{2}{*}{ Variables } & \multicolumn{4}{|c|}{ Sexually initiated } \\
\hline & Yes $=108$ & $\mathrm{No}=\mathbf{3 1 0}$ & Crude OR (95\% CI) & Adj. OR (95\% CI) \\
\hline \multicolumn{5}{|l|}{ Age } \\
\hline $15-19$ & $69(20.1)$ & $275(79.9)$ & $0.225(0.133,0.381)$ & $0.225(0.133,0.381)^{*}$ \\
\hline$\geq 20$ & $39(52.8)$ & $35(47.31)$ & & \\
\hline \multicolumn{5}{|l|}{$\overline{S e x}$} \\
\hline Male & $70(25.8)$ & $201(74.2)$ & $0.999(0.631,1.580)$ & $0.999(0.631,1.580)$ \\
\hline Female & $38(25.9)$ & & $109(74.1)$ & \\
\hline \multicolumn{5}{|l|}{ Residence } \\
\hline Urban & $53(26.1)$ & $150(73.9)$ & $1.028(0.663,1.593)$ & $1.028(0.663,1.593)$ \\
\hline Rural & $55(26.6)$ & $160(74.4)$ & & \\
\hline \multicolumn{5}{|l|}{ Marital status } \\
\hline Not married & $14(37.8)$ & $23(62.2)$ & $1.818(0.919,3.781)$ & $1.818(0.919,3.781)$ \\
\hline Married & $94(24.7)$ & $287(75.3)$ & & \\
\hline \multicolumn{5}{|l|}{ Religion } \\
\hline Christian & $67(25.8)$ & $193(74.2)$ & $0.991(0.632,1.556)$ & $0.991(0.632,1.556)$ \\
\hline Muslim & $41(259)$ & $117(74.1)$ & & \\
\hline \multicolumn{5}{|c|}{ Parental attachment } \\
\hline Live alone & $36(22.2)$ & $126(77.8)$ & $0.332(0.153,0.434)$ & $0.332(0.153,0.434)^{*}$ \\
\hline Live parents & $72(28.1)$ & $183(78.2)$ & & \\
\hline
\end{tabular}

*significant

\section{Discussion}

As part of the larger social system, a number of factors affect adolescents' attitude and behavior. The field of adolescent health has focused on those risk factors that predispose adolescents to health and social problems. Such as: early sexual initiation, multiple sex, unprotected sex, substance abuse and other related practices leading a negative outcome of behaviors. [10,21].

This study revealed that, the overall knowledge of the participants found to be high. About $79 \%$ who participated in the study have good knowledge about the questions used to assess the level of knowledge on sexual behavior. The study has shown that having a level of good knowledge didn't guarantee students from practicing risky sexual behavior. A considerable proportion of the participants 108(25.8\%) reported as they had one or more sexual intercourse in their life time. This finding is comparable with the study conducted among Gondar College of Medical sciences by in 2004(22). That is $25.3 \%$ of the study subjects were reported as they were sexually active.

More than half of the sexually active participants $58(53.7 \%)$ reported as they had more than one life time partner and this was more evidenced by the male participants than the females. Most of the sexual relations made with more than one partners were found to be risky and potentially infective. Out of $17.1 \%$ of male students who reported sexual intercourse with commercial sex workers during the study, $16.7 \%$ fail to use condom or committed unprotected sex. Sexual intercourse with commercial sex worker was greater as compared to what was reported among Gondar college of medical science students in 2004(17.1\% versus $7.8 \%)(22)$.
Consistent use of condom among those who were in multiple sexual intercourse was $26(24 \%)$ and the overall condom use at first sexual debut was only $43(39.8 \%)$. This means that a large proportion of sexually active school students were practicing sex without any protection. As the number of sexual partner increases the use of condom deceases. This implies, the more frequently individuals are practicing sex with multiple partner; he/she fail to use condom. The study also revealed, both male and female students engaged into sexual practice at their teens. The mean age at first sexual debut for male and female students was nearly the same (16.5 year for males and 16.2 year for females). Moreover, similar proportions of male and female students were ever had sex in their life time. That is 70 ever had sex out of 271 male students and 38 ever had sex out of 147 female students, and making $25.8 \%$ for male and $25.9 \%$ for females.

This finding was incomparable with the study conducted in 1990-91 academic year student of Gondar College of medical sciences " $49.5 \%$ of the boys and $18.3 \%$ of the girls had experienced sexual intercourse." But comparable with the study made in Bahir Dar University students in 2003, that is 18.8 years $(24,25)$.

About 92(85.2\%) of the participants who practiced sex, had history or sign and symptoms of sexually transmitted infection. Of whom male student account $85 \%$ and females $84 \%$. And out of those who had the disease only $38 \%$ of male and $55 \%$ of female were treated by the time they had the sign of the disease. A total of 46 students were reported substance use and the majority being males $97.8 \%$. Khat was the most dominant and familiar type of substance used by $86.7 \%$ of the students. About $13 \%$ of male students consume alcohol to arouse sexual intercourse. None of the students reported khat use for sexual arousal. Female students who engaged in 
sexual practice, $44.7 \%$ encountered unwanted pregnancy and $94 \%$ of them committed abortion, and of which $25 \%$ committed two and more times. This figure is the highest as compared to unsafe abortion committed by young girls in some of African countries. The prevalence of Voluntary counseling and testing was $46.8 \%$. The reason for testing was mainly to know self status $(93.5 \%)$ followed by commit sex, and to get marry. About $85(20 \%)$ of the respondents were justifying fear of positive result as a reason for not testing ( $22.1 \%$ male and $17 \%$ of females) followed by the service was not available (11.8\% for male and $10.8 \%$ for females).

The multivariate analyses of selected variables: age, condom use and substance use have shown that there is statistically significant association between students' risky sexual behavior.

And age and poor parental attachment were associated with students' sexual initiation. Respondents whose age is between 15-19 years were three times at risk of having risky sexual behavior than age group above 20 years, Adj. OR, 95\% CI $2.899(1.720,4.887)$, Condom users are protected from risky sexual out comes as compared to none condom users, adj. OR, $95 \%$ CI, $0.470(0.285,0.775)$.

\section{Limitations of the Study}

Possibility of under reporting for very sensitive issues (social desirability bias). Though the study was representative for a particular zone (Gurage zone), we can't generalize for the rest of the regions and/or the nation. For the limitation of resource (time and finance) and hence all factors determining risky sexual behaviors were not included in a wider range in the study. Very limited similar studies in preparatory schools were conducted far and hence difficult to make competitive comparison and discussion.

\section{Conclusion}

The study has revealed that young people in preparatory schools, despite having good knowledge about sexual health and its unwanted consequences, a significant proportion of them were found to be practicing risky sexual behaviors and associated untoward consequences are wide spread among school adolescent.

Due emphasis need to be given to alleviate the problems. Instituting youth friendly reproductive health services in schools, Addressing behavior change communication strategies with their involvement, developing the practice of open and regular discussions with the main actors and strengthen parent and child relationship, empowering female students starting from the lower grades and further and wide range of studies were recommended by the investigator.

\section{Acronyms}

ACIPH --- Addis Continental Institute of Public Health

AIDS -- Acquired immune Deficiency Syndrome

ART --- Anti Retro Viral Therapy

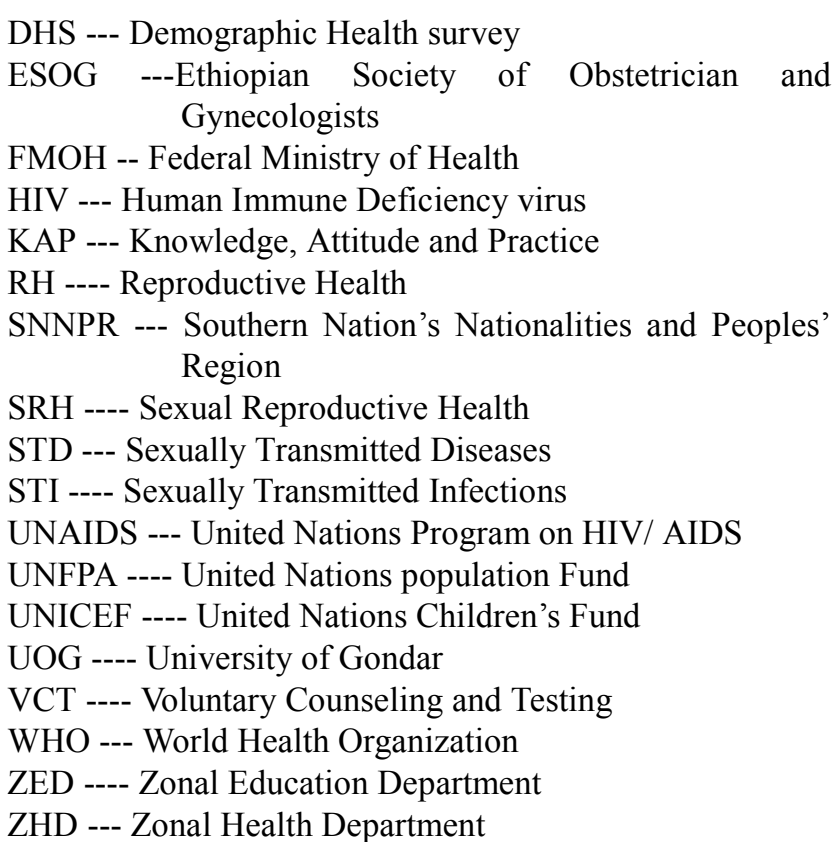

\section{Acknowledgment}

Above all, my heartfelt appreciation goes to my advisors Dr. Mitike Molla and Prof Yemane Birhane for enriching me with valuable ideas and continuous support starting from the inception of the study to the final report writing and constructive criticism. My gratitude extends to the officials in SNNPR health bureau, SNNPR education bureau, Gurage zone health department, Gurage zone education department, directors and unit leaders of the schools enrolled in the study (Wolkite, Imdiber, Butajira, Agena and Buee preparatory schools), all the study participants (students, health care providers from Gurage Zone public and private health facilities, and teachers).

\section{References}

[1] United Nations: World population prospective, the 2000 revision, Volume 1, 2001

[2] WHO (1999). Programming for adolescent health and development, Report of WHO/UNFPA /UNICEF study on health programming for adolescents Tech. report Series No. 886. WHO, Geneva

[3] WHO: HIV/AIDS and young people: WHO takes action. September 2004, Brief.

[4] CRLP (1997). Women of the world: Law and Policies Affecting their Reproductive Lives, Anglophone Africa.

[5] MOH (1998). Reproductive health Needs adolescents in Dessie preparatory school Students. Sep. 2004, page 57.

[6] Federal Ministry of Health: National Adolescent And Youth Reproductive Health strategy 2007-2015, 2: 12-13, ADDIS Ababa, 2006.

[7] WHO: Riskand Protective Factors Affecting Adolescent Reproductive Health IN Developing Countries, Geneva, 2006 
[8] Ethiopian Public Health Association: Young People's HIV/AIDS and Reproductive Health Needs and Utilization Of Services in Selected Regions of Ethiopia. Addis Ababa, 2005

[9] WHO: Adolescent Friendly Health Service An Agenda For Change, 2003

[10] Joint United Nations Programme on HIV/AIDS, 2004 report of the global AIDS Epidemic http://www.unaids.org, accessed on June, 2009

[11] Dehane KL, Reider G, Sexually transmitted infections among adolescents: the need for adequate health service, Geneva: world Health Organization, 2005

[12] WHO. Global prevalence and incidence of selected curable sexually transmitted infections: over view and estimates. Geneva: World Health Organization, 2001.

[13] D, Singh S. Frost JJ. Differences in teenage pregnancy rates among five developed countries: the roles of sexual activity and contraceptive us. $2001 ; 33: 244-50$.

[14] WHO: Risk And Protective Factors Affecting Adolescent Reproductive Health In Developing Countries, 2006, 7: 145165.

[15] WHO (1999) programming for adolescent health and development, Report of WHO/UNFPA/UNICEF study on health programming for adolescents. WHO, Geneva.

[16] Solomon Shiferaw: The effect of living arrangement and parental attachment on sexual risk behavior and psycho-social problems of adolescent in Dessie preparatory school, Ethiopia EPHA, 2004, Addis Ababa.
[17] Ethiopian Democratic Republic of Ethiopia, Ministry of Health, Addis Ababa University, HIV/AIDS prevention and control office: HIV/AIDS behavioral surveillance survey, 2002.

[18] Tesfay F, Kassaye M,: Community based survey of STD syndrome in Adami Tulu Ethiopia Journal of Health 2000, 14: $7-12$.

[19] Adamu R, Mulatu MS: Sexual initiation and risk behavior among Ethiopian high school Student, 2000.

[20] Mekbib T, G/Hiwot Y and Fantahun M (2002). Survey Of Unsafe Abortion In Selected Health Facilities In Ethiopia (unpublished Report)

[21] American Journal of health: HIV-AIDS, STI education in schools, colleges, universities and Jail, 2007.

[22] Jack and Jill: Facts about Substance abuse and risky sexual behavior, 2000

[23] Blanc A, way A. Sexual behavior, contraceptive knowledge and use 1998: 29: 117

[24] Yohannis Fitaw, Alemayehu Worku; High-risk sexual behavior and pattern of Condom Utilization of the Gondar College of Medical Sciences (GCMS) students, North- west Ethiopia, Oct. - Nov. 1999.

[25] Ethiopian Medical Journal, College Students' Attitudes and knowledge of aids. 1993 Oct 31 (4): 233-7.

[26] Amsalu Shiferaw: Response to HIV/AIDS, North west Ethiopia, 2003 2: 7-8 